\title{
The Practice of English Language Teaching Through Literature at Secondary Schools in Ethiopia Focusing on Attitudes of Teacher's and Student's
}

\author{
Antehun Atanaw and Rashmi Gaur \\ Indian Institute of Technology Roorkee, India
}

\begin{abstract}
Teaching and learning of a language couldn't be performed separately without understanding the culture and the custom of the language under study. Therefore, in English language teaching through literature at secondary school cultural values and/or impacts of culture should be clearly stated by the language teachers to their students since the cultural issues retain a direct relationship to determine the meaning of words uttered and written by speakers of the language. Literature properly exposes students to complex themes and afresh, unexpected uses of standard language. A good novel or short story can gently take the students to foreign countries and fantastic worlds. A play or a poem can bring up certain dilemmas and dynamic emotional responses. This paper analyses literary texts incorporated in students' textbook, incorporate researcher teaching English language experience and look out the curriculum objectives for the grade level. In the Ethiopian context, intercultural understanding has got little attention; communicative competence and linguistic competency gain relatively prioritized. If institutions and concerned bodies are looking for better learners who are well skilled with the target language; they have to properly incorporate contents which focus on enhancing trainees' awareness and use suitable language teaching methods for better implementation.
\end{abstract}

Keywords: Literary text, English language teaching, Short story

DOI: $10.7176 /$ JLLL/82-01

Publication date:October $31^{\text {st }} 2021$

\section{Introduction}

Ethiopia is the country that is located in the horn of Africa with 1.12 million square kilometer space and having around 110 million people (Worldometer). Education in Ethiopia had been dominated by the Ethiopian Orthodox church for many centuries, and modern education was introduced to Ethiopia nearly a century ago. However, the education and training offered during these long years had limited positive impact on the lives of the people and national development. The education offered was incapable of solving the problems of farmers, pastoralist, and changing the lives of the overwhelming majority of the people (Negash, 2006).

The introduction of the English language in the education system of Ethiopia came along with the history of modern (Western) schooling which dates back to 1908. The beginning of modern education in Ethiopia was characterized mainly by teaching foreign languages such as French, English, and Italian. It took place with the belief that "These languages would be important to keep the country sovereign by providing the country with elites who could negotiate to the interest of the country through the international tongues (Minister of Education). Among the foreign languages such as French, Italy, and English which were taking part in the education system of Ethiopia in previous time only English language has been retained till now in the education system and it has got great consideration since the English language is very important for the economic development of the country. It is also the language that has great function across the world in international relation, commerce, trade, science, and technology some among many functions and Ethiopia as a country taking part in these and others situation in the world so that teaching the English language becomes mandatory to Ethiopia (Federal Democratic Republic of Ethiopia Minister of Education, 2002).

According to (Chouhan, n.d.) in his article (2016) in recent years, the role of literature as a basic component and source of authentic texts of the language curriculum, rather than an ultimate aim of English instruction, has been gaining momentum. Among language educators, there has been a hot debate as to how, when, where, and why literature should be incorporated in English as a second language or English as a foreign language (ESL/EFL) curriculum. Vigorous discussion of how literature and ESL/EFL instruction can work together and interact for the benefit of students and teachers has led to the flourishment of interesting ideas, learning, and improved instruction for all. Many teachers consider the use of literature in language teaching as an interesting and worthy concern.

Even though using literature for teaching the English language is very important, it is highly recommended to give attention to literary text selection. Literary text selection should be performed very carefully. When language teachers select literary texts they should take into account the needs, motivations, interests, cultural background, and language level of the students. Selecting books significant to the real-life experience, emotions, or dreams of the learner is of enormous importance (Hişmanoğlu, 2005). 
Therefore, English language teaching through literature provides significant importance to the EFL/ESL learners, acquiring basic language skills and intercultural understanding is certain if teachers implement English language teaching through literature with appropriate language teaching approach during the actual classroom.

\section{Literature Review}

\subsection{Intercultural understanding}

In language studies, there are different things that took place simultaneously with the acquisition of language skills and language areas (vocabulary, grammar, and pronunciation). Among them, intercultural understanding is one and very crucial concept that language teachers need to take into consideration during second language or foreign language teaching and learning. Teaching and learning of certain language couldn't be performed separately without understanding the culture and the custom of the language under study. Therefore, in English language teaching through literature at secondary school cultural values and/or impacts of culture should be clearly stated by the language teachers to the students since the cultural issues have a direct relationship to understand the meaning of words uttered and written by speakers of the language.

Intercultural understanding provides priority to culture and situates it as a core for meaning formation because it takes the lion share for the discussion. Raymon William (Qt. in Williams-G) has famously argued that culture which is the meaning of few words that we occur in the English language. As many scholars suggested the study of one's language highly interlinks with its cultural value and culture is perceived as something to be acquired, a body of knowledge and skills to be taught (Williams-Gualandi, 2015)

In teaching English language through literature at secondary school the primary focus is on developing the basic language skills (listening, speaking, reading and writing) and language areas (grammar, vocabulary and pronunciation) of the learners through using literature which includes contents that let students learn the target points inseparably; at this time the teacher should be aware of the cultural features which exist in the literary texts because the culture is a center to understand the meaning of the literary text. Hence, the teachers basically need to dig out primarily the cultural features which are incorporated on the literary texts which will be used as an authentic teaching aid.

Byram Michael qtdin (Williams-Gualandi, 2015)stated that attention has to be given for language teaching and learning; teaching a language is highly rely on teaching the culture of that language. Foreign language acquisition is the same as acquiring the culture, custom, belief, and practice that belong to certain social groups'. Learning a language simply is not the ability to grasp knowledge about it. It is also the ability to naturalize the language that is under study as their own first language. In learning language, the outcome that is expected from the learners is to make the language like their own mother tongue language. Therefore, the course is not only in adding something on the mind of the learner it also tries to relate and make the language their natural language. Linguistics competence and intercultural competence couldn't able to deliver separately because they are like the two sides of the coin. They are not simply separated and addressed in different time. Furthermore, intercultural communicative competence is the issue that has relation with those two issues and some scholar suggested there is slice difference among them and it is better to look them one by one.

$>$ Linguistics competence: - is thought of as the ability of the learners to form well-structured sentences and the skill of comprehending the given sentences based on their knowledge of grammar and syntax of the language (Choudhary, 2016)

$>$ Intercultural communicative competence the intercultural communicative competence (ICC) is attained in the context of language learning and the accurate way to perform in the language.

$>$ Intercultural competencies based on components such as intercultural attitudes, knowledge, skills, and shared values in a given society. The foundation is on the attitudes of the intercultural speaker.

Moreover, Sandra L. states that it is necessary to evaluate the materials or resources available prior to their use in our classes, as often times the materials included in books may indeed be constraining or perpetuating a stereotype, instead of helping students understand diverging cultural practices. It is important for students to be further challenged and guided in order to develop critical communicative skills. Furthermore, as we strive to create the right conditions, Byram M. Qtd in (López-Rocha, 2016) suggests that the focus should not be solely on preparing students to communicate without mistakes, but to communicate openly, forging relationships that will allow them to thrive in the foreign cultural context. We need to help students develop intercultural awareness and provide activities where the "other's" culture, values, and behaviors are considered. In order to allow students to learn about themselves and others, we can use stereotypes, but only in order to deconstruct them and address misperceptions. Students will also need to first understand, and then explain, the sources of intercultural conflict and how to deal with them, while avoiding misunderstandings. Ultimately, we want to help students become intercultural competent speakers.

Based on what is stated above we can understand that language teaching in EFL/ESL classroom is not performed separately from culture, linguistic, language form and language area; in the real classroom teaching the material which the teachers are using needs to be selected in a very careful manner. They are authentic 
engines that learners are going to interact and grasp sort of information. According to (Hişmanoğlu, 2005)when language teachers select literary texts they should take into account the needs, motivations, interests, cultural background, and language level of the students. These issues have a place in literary texts that are selected with great care, and through material preparation and selection, teachers should not deny the importance of literary texts which are vital resources which incorporate the points that need to be acquired during English language teaching in EFL/ESL classroom. In language teaching through literature at secondary school, the literary texts that the teacher is going to use as an aid to arise the emotion, interest, and feeling of the students should be selected with great care of assuring that the material has incorporated the intended points altogether.

\section{Experience of teaching English language through literature at Ethiopian secondary schools}

The education and training policy and its implementation document (Federal Democratic Republic of Ethiopia Minister of Education, 2002)says that the reasons why English is taught as a subject from the first grade to grade eight are that the language is not spoken at home and students experience the language only in the school. Thus, early familiarity with English helps students to get enough time to develop basic skills when they advance to secondary school where the medium of instruction is English.

In relation to the mother tongue language policy that provides a room for people to practice their mother tongue language is advisable for one country to see the presence of democracy and it can be considered as one factor. But the challenge students' encounter is that they are unable to cope up with the secondary education situations because of their inefficient ability of English language.

In order to overcome this challenge the Minister of Education and Every Regional State Education Bureau are doing different tasks like, curriculum revision, book revision, establishing English Language Improvement Centers \& English Language Improvement Program, providing different training for students to enhance their skill, and providing in-service training for teachers to enhance, develop and adopt different language teaching approaches. Nevertheless, many activities are performed still the performance of the usage of the language in the real context is ineffective.

On students' textbook, there are literary texts which are incorporated to facilitate the language teachinglearning process. Scholars agree that literature is authentic material for language teaching(Lazar, 1993), (Nelson $\&$ Nelson, 2018).In order to evaluate the appropriateness of the literary text (Lazar, 1993)checklist is used at the time of evaluation. Based on the criteria some of the literary texts have been evaluated the texts are situated on

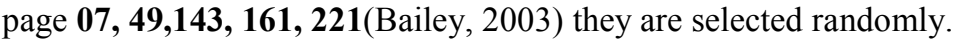

On the bases of the checklist cultural, linguistic, and literary background of the students were taken into account. Ethiopian students learn English as a foreign language and many of secondary school students are living in the rural area because of this and other cases cultural of students have challenge related to understanding cultural issues related to most of the literary texts. About the literary background since students were learning English as a subject for eight years and more they are expected to have good performance in reading and comprehending literary texts which are stated on their textbook but few of the students have the ability to read and comprehend. Therefore, it is mandatory to evaluate texts and check students' performance before going to the basic contents. According to (Chouhan, n.d.)Literature provides learners with a broad variety of individual lexical or syntactic items. Students become acquainted with many types of written language, reading a considerable and contextualized body of text. Literature plays an important role in teaching four basic language skills like reading, writing, listening and speaking and language areas for example vocabulary, grammar and pronunciation are very popular within the field of language learning. Therefore, language teachers need to be aware of the important functions of literature in helping students acquire the target skill. Linguistic background has a small place than cultural and literary background and teachers teach English subject focusing on grammar/structure; students also emphasize on it because the experience of Grade 10 National examination "Ethiopian General Secondary Education Certificate Examination (EGSECE) focus on grammar and it didn't has place for writing, listening and has little place for speaking.

Additionally, there are other factors that should be considered when literary text selection takes place. These are the availability of texts, length of texts, exploitability and fit with the syllabus. As it is mentioned earlier most of the secondary school students are living in a rural area and the availability of the material has some difficulties and the distribution of the textbook is one to two/three; the length of the literary texts almost all of secondary school students' textbook incorporate very short literary text (one or two pages long). At this grade level students are expected refresh and expand what they have learned before; so that students are expected to read more by themselves if they cannot do and if teachers read to them and translate using their native language there would be passive students (Choudhary, 2016).

In relation to exploitability of literary texts and tasks related to texts, the major challenge is that students' textbook is prepared by the minister of education at the center and dispatch in all side of the country. This is the only material that most of the language teachers rely on and some are incapable to design and select appropriate literary text for the grade level. Furthermore, the text link with the rest of the syllabus grammar, vocabulary with 
the methodology should be fit with each other. According to (Nagi, n.d.) in his article the preconception, that literature is a difficult subject, is making a gap between the teachers and learners of English. This approach needs very skillful teachers who can read the needs of their learners. The syllabus should be chosen carefully to be upto the standard of the learners especially if the learners are from the rural area. Therefore, literary texts incorporated on students' textbook need some more verification considering students interest, motivation, emotion, and linguistic proficiency. There is grammar and vocabulary related exercises that are designed based the literary texts. The problem is that the way literature is instructed during the actual session. Usually, they deliver literary texts with simple reading aloud.

The final expectation or outcome of Secondary school syllabus is to produce skillful students who are effective in utilizing the target language (English) in all situation of their future career either grade $11^{\text {th }}$ and $12^{\text {th }}$ and at a college or in the world of work. Taking this into account the literary texts which are incorporated in the textbook should be delivered or instructed in a way that can enhance students' intercultural competence. Furthermore, the training that secondary schools English language teachers are attending needs to add some courses which focus on awareness creation on how to integrating literary texts and how to help students develop intercultural competence during their study the target language.

Moreover, in my own experience as a high school teacher, I had observed and discussed with some English language teachers that students are obliged to learn 10 courses. Among this English is one of the subjects they are attending and the subject has only one student textbook with around 250 pages with ample exercises and the other subjects too. Thus, teachers are unable to support their students because of the difficulty to get time for the tutorial and other classes. Moreover, the teachers are also inefficient to deliver the course as it is stated in the curriculum; (Heugh \& Benson, 2007)in their research report stated that teachers throughout the system have extremely limited competence in the English language and extremely limited exposure to English outside the classroom. Few can cope with the demands of teaching English as a subject, and even fewer with the challenges of using English to cover curricular contents. There is a large gap between aspiration for English and what is possible with the socio-economic and educational realities of the country. To deal with the intended objectives and minimize the challenges it is obligatory to select teaching approaches which are appropriate to obtain the expected outcomes and need to conduct further study on this issue.

\section{Approaches in teaching literature at English as Foreign Language Classroom}

The history of language teaching dates back to many centuries, and teaching the language practiced using various language teaching methodologies which were implemented during teaching the language (Brown, 2000). In this time English is the language which has got top position to be taught all over the world since Latin language had lost the highest rank which was occupied by it. In teaching English language there were many language teaching methodologies which were in practice to deliver the instruction, since grammar translation to the current communicative language teaching method there is no an absolute and holistic teaching method that can serve in all situations. English language teaching is not only focusing on good communication skill but also giving an emphasis to the acquisition of language areas and developing intercultural understanding. To attain these objectives, there have to be teaching approaches that instructors should use during lessons instructing.

Nagi in his article states that teaching English through literature is an effective method especially if it is done through effective tools. The teacher is the catalyst in this process. If $\mathrm{s} / \mathrm{he}$ is chosen carefully, s/he will do his/her best. Also, students are the corner stone in the process of learning English through literature. Students have different skills and needs. The literary texts should be up to the needs of the learners. Motivation encourages talented students. Literary texts are varied and they should meet the talents of students. Students should participate in the selection and production of these literary texts.

According to (Lazar, 1993) there are lists of approaches which are recommended to be used in teaching literature at EFL classroom. Among them Reader - Response, Language - Based and Stylistics approaches are some among the others. These approaches are not approaches which are focusing only teaching literature; simultaneously they provide room for language aspects. Therefore, teachers should implement these approaches in a well structured manner to obtained valuable result on the actual teaching language practice.

\subsection{Reader-Response Approach}

The major principles of the reader-response approach include attention on the role of the reader and a processoriented approach to reading literature. This encourages students to draw on their personal experiences, opinions, and feelings in their interpretation of literature. Dias and Hayhoe(1984) qtd in (Rakhees, 2014)pointed out that "it is precisely the role of the reader in the act of reading that has not been sufficiently and properly addressed".

The reader-response approach addresses this problem by making the learners' active participant in the learning process. The crucial connection between the reader and the text is explained by Rosenblatt's theory of literary reading, which describes the transactional relationship between a reader and a literary work. The events that take place in a literary work occur at a particular time and place, and different readers react to these events 
in different ways, depending on their unique interests, emotions, needs and experiences. Each reader attaches his or her own personal interpretation to a literary work. Meaning creation and learning are not an easy task unless till learners interact actively with the text.

The reader-response approach, as a matter of fact, makes an important contribution to language learning by demystifying literature and connecting it to individual experience. Researchers and teachers in the field of language learning support making literature more accessible by activating students' background knowledge so they may better predict and decode the language and themes of literary texts. Emotional reactions from reading a story, poem, or play can be harnessed for classroom instruction. Activating students' schemata in reading literature is important and personalizing the learning experience increases student participation and motivation. These are the core principles of communicative language teaching that are known to encourage learning through student-centered and process-oriented activities.

\subsection{Language-Based Approach}

The language-based approach emphasizes awareness of the language of literature, and it is the basic stage for language learners. This approach facilitates students' responses and experience with literature and is considered quite accessible for language learners. In addition, the language-based approach calls for a variety of language instruction activities, including brainstorming to activate background knowledge and make predictions, rewriting the ends of stories or summarizing plots, using closed procedures to build vocabulary and comprehension, and incorporating jigsaw reading to allow students to collaborate with others, form opinions, and engage in spirited debates. Thus, literature is an excellent vehicle for communicative language teaching methods that result in developing language skills through interaction, collaboration, discussion, and collective learning. The teacher's role is not to impose interpretation but to introduce and clarify difficult and technical terms, to prepare and offer appropriate classroom procedures, and to intervene whenever necessary to provide prompts or stimuli.

The language-based approach responds to language students' needs in studying literature: They receive the skill and technique to facilitate access to texts and develop sensitivity to different genres so that they may enjoy a piece of literature that relates to their lives. Moreover, this approach meets students' needs in learning a language better; they communicate in English to improve their language competence, develop the necessary skills of working in groups, and become active learners. Most educators agree that the language-based approach is motivating, as it helps students handle a text, enhances their enjoyment and interest in literature, develops their autonomy and improves their learning of English.

\subsection{Stylistics Approach}

According to Maley (1989) in his article stated that "this approach is closely in tandem with what EFL/ESL teachers need for their language classes where the focus is on literature as "text'", Qtd in (Jelena Bobkina and Elena Dominguez, n.d.). The stylistics approach concerns itself with the use of linguistic tools to analyze literary texts. It leads learners into full understanding and appreciation of literature in the light of linguistic analysis and literary criticism. Consequently, learners will see how language is exploited in literary works to communicate certain messages to the addressees (Lazar, 23). There are two aims of this approach: "firstly, it enables students to make meaningful interpretations of the text. Secondly, it helps to expand students' knowledge and awareness of the language". Then, the goal of the stylistic approach is to attract students' attention to the linguistic features of literary texts, helps them read literature more completely.

\section{Conclusion}

In any language teaching there are lots of things which have taking place simultaneously in the actual session. The practice of teaching English language through literature is one and major way of language teaching methodology that should be taking place with a very structured and well organized condition. In this situation learners are able to acquire language forms, language areas and try to develop intercultural understanding of the English language they are studying. In Ethiopian context the teaching of English language is still incapable to attain the intended objective. In order to overcome this challenge it is obligatory to conduct further studies relation to English language teaching in Ethiopia. One thing that should be remembered during utilizing literature as a tool on delivering instruction in English as a Foreign Language classroom; literature is not an end by itself it is a mechanism which supports teachers to drive the necessary contents that students are expected to learn.

\section{Bibliography}

Bailey, D. (2003). English for Ethiopia Students Textbook Grade 9. Federal Democratic Republic of Ethiopia Minister of Education.

Brown, H. D. (2000). Principles of Language Learning and Teaching 5th ed. Pearson Education, 10 Bank Streee. Choudhary, S. (2016). Literary Approach to Teaching English Language in a Multicultural Classroom. Higher 


Learning Research Communications, 6(4), 1-6. $\quad$ Retrieved from
https://search.proquest.com/docview/1858869508?accountid=14089\%5Cnhttps://eu.alma.exlibrisgroup.com /view/uresolver/44UOC_INST/openurl?genre=article\&atitle=Literary + Approach + to + Teaching + English + La nguage + in $+\mathrm{a}+$ Multicultural + Classroom\&author $=$ Choudhary $\% 2 \mathrm{C}+$ Sanj

Chouhan, A. (n.d.). Teaching English Language through Literature : A Critical Study Ashwin Chouhan English faculty RGUKT ( IIIT ) Basar, 266-271.

Federal Democratic Republic of Ethiopia Minister of Education. (2002). The Education and Training Policy and Its Implimentation. Federal Democratics Republic of Ethiopia Ministry of Education.

Heugh, K., \& Benson, C. (2007). Final Report Study on Medium of Instruction in Primary Schools in Ethiopia Commissioned by the Ministry of Education September to December 2006, (December 2006).

Hişmanoğlu, M. (2005). Teaching English through literature. Journal of Language and Linguistic Studies, 1(1), 53-66. https://doi.org/10.17263/jlls.38648

Jelena Bobkina and Elena Dominguez. (n.d.). The Use of Literature and Literary Texts in EFL Classroom; Between Consensus and Controversy.

Lazar, G. (1993). Literature Language teaching A guider for teachers and trainers. Cambrige Teacher Training and Development.

López-Rocha, S. (2016). Intercultural communicative competence: creating awareness and promoting skills in the language classroom. Innovative Language Teaching and Learning at University: Enhancing Participation and Collaboration, (2016), 105-111. https://doi.org/10.14705/rpnet.2016.000411

Nagi, A. T. A. (n.d.). Teaching English through Literature: A Creative Trend.

Negash, T. (2006). Education in Ethiopia From Crisis to the Brink of Collapse. Nordiska Afrikainstitutet, Uppsala.

Nelson, R. J., \& Nelson, R. J. (2018). The Role of Literature in Foreign Language Learning, 32(5), 456-460.

Rakhees, A. A. (2014). The Role of Literature in Teaching and Learning English as a Foreign Language. Open Education College in Basrah.

Williams-Gualandi, D. (2015). Intercultural Understanding:

What are we looking for and how do we assess what we find? Working Papers Series, 1-29.

Bio-Profiles:

Antehun Atanaw is a $\mathrm{PhD}$ student at the Indian Institution of Technology Roorkee. He obtained his MA in TEFL at University of Gondar; his interest area is English Language Teaching, Communicative English Skills; it is possible to reach him through his email antehuns@gmail.com/amengistu@hs.iitr.ac.in

Dr. Rashmi Gaur is an Associate Professor of English Literature in the Department of Humanities and Social Sciences at Indian Institute of Technology Roorkee. She had got her PhD in English Literature from ... her interest area is English, Professional Communication, Culture and Gender theories, Mod. Fiction, Indian Writing. She can be reached at rashmigaur.iitroorkee@gmail.com 